\title{
Drug management in chronic rhinosinusitis: identification of the needs
}

\author{
Jean-Baptiste HPJ Watelet' \\ Philippe H Eloy ${ }^{2}$ \\ Paul B van Cauwenberge' \\ 'Department of Otorhinolaryngology, \\ University of Ghent, Ghent, Belgium; \\ ${ }^{2}$ Department of Otorhinolaryngology, \\ CHU Mont-Godinne, Université \\ Catholique de Louvain, Yvoir, Belgium
}

Correspondence: JB Watelet

Department of Otorhinolaryngology,

University of Ghent, UZ Gent IPI,

De Pintelaan, I85, B-9000 Gent, Belgium

Tel +3292402332

Fax +3292404993

Email jeanbaptiste.watelet@ugent.be

\begin{abstract}
Chronic rhinosinusitis (CRS) is a group of multifactorial diseases characterized by inflammation of the mucosa of the nose and paranasal sinuses with a history of at least 12 weeks of persistent symptoms despite maximal medical therapy. The precise role played by infection and immunoglobin E (IgE)-mediated hypersensitivity remains unclear. Diagnosis of CRS is based upon medical history, nasal endoscopy and computed tomography scan of the sinuses. The CRS with polyps visible in the middle meatus must be distinguished from the CRS without polyps. Based on the current knowledge about the pathogenesis of CRS, it is admitted that an optimal medical treatment must consider all favorizing factors and control efficaciously the inflammation process. In case of failure of medical treatment, endoscopic sinus surgery should be proposed. However, some well-validated data and scientific evidences are missing, even for the most frequently used medications. After a review of the actual definitions and classifications, a short description of the current knowledge about pathogenesis of CRS is provided in order to justify the actual therapeutic rationales and identify the needs for an effective treatment of CRS. Keywords: rhinosinusitis, pathogenesis, diagnosis, management, guidelines
\end{abstract}

\section{Introduction}

Rhinosinusitis is one of the most common healthcare complaints in US and Europe (Van Cauwenberge and Watelet 2000). The burden of affected individuals in terms of decreased productivity, absenteeism from the workplace, and diminished quality of life, when added to the costs of care and growing public health menace of antibiotic-resistant bacteria, makes rhinosinusitis a serious disease (Winstead 2003). Affecting nearly 16\% of the adult population annually (Anand 2004), rhinosinusitis induces subsequent direct and indirect costs: in 1996, in US, the annual medical expenditure for sinusitis was US $\$ 3.39$ billion and the indirect costs due to lost work were nearly US $\$ 3.8$ billion (Ray et al 1999). Because of this significant impact on public health and socio-economy, rhinosinusitis warrants precise diagnosis and effective therapy.

Several position papers and guidelines on rhinosinusitis have been recently published by experts or scientific societies (Grevers and Klemens 2002; Anon et al 2004; Brink et al 2004; Ressel 2004; Varonen and Saino 2004; Blomgren et al 2005; Klossek and Federspil 2005; Poole and Portugal 2005; Wright and Frenkiel 2005). In December 2004, The American Academy of Allergy, Asthma and Immunology, The American Academy of Otolaryngic Allergy, The American Academy of Otorhinolaryngology-Head and Neck Surgery, The American College of Allergy, Asthma and Immunology, and The American Rhinologic Society developed consensus definitions for rhinosinusitis and strategies for patient care (Meltzer et al 2004a, 2004b). This expert panel composed of allergists, otorhinolaryngologists, microbiologists, and radiologists outlined criteria for research dealing with pharmacologic and surgical intervention in rhinosinusitis. More recently, the European Academy of Allergology 
and Clinical Immunology (EAACI), in close collaboration with the European Rhinologic Society, updated the knowledge of rhinosinusitis and nasal polyposis and provided evidencebased medicine documents (Fokkens 2005) on diagnosis methods and available treatment for rhinosinusitis (Fokkens et al 2005a, 2005b).

From these reviews and consensus, it appears that the recent innovations in endoscopy, imaging and biology have considerably improved our understanding of sinus pathogenesis. However, from a general practitioner or Ear, Nose, and Throat (ENT) specialist point of view, the diagnosis of rhinosinusitis remains mainly clinical and the treatment is usually empiric, even if, especially when considering chronic rhinosinusitis (CRS), it is now admitted that rhinosinusitis is not simply an infectious disease but a complex and multifactorial disorder. Finally, the development of new medications has significantly increased the therapeutic possibilities for the drug management of CRS.

Interestingly, when considering the literature on the drug management of CRS, it appears that many questions remain unanswered and scientific evidence is dramatically missing. In this paper, after a short description of the clinical and biological background of CRS, the major needs for research in drug management of CRS are identified.

\section{Definitions}

Different types of definitions can be found in the literature on chronic rhinosinusitis. Some of them are dedicated to clinicians, general practitioners, or specialists, while the others are specifically designed for epidemiological surveys or research.

In 2003, a task force convened by the Sinus and Allergy Health Partnership defined chronic rhinosinusitis as a group of disorders characterized by inflammation of the mucosa of the nose and paranasal sinuses of at least 12 weeks duration (Benninger et al 2003). As recently claimed by the American Position Paper (Meltzer et al 2004a), objective documentation is required by means of direct visualization of the middle meatus through anterior rhinoscopy, nasal endoscopy to assert the accurate diagnosis of CRS. For the American experts, although rhinosinusitis can be diagnosed in the majority of patients by using only clinical judgment, patients with recurrent or complicated sinus disease might require imaging studies. Imaging is also considered as absolute requirement for the research on CRS.

In the EAACI position paper, the definition of CRS relies on positive computed tomography (CT) changes even in the definition designed for daily practice (Table 1). For research purposes, attention must be paid on the presence or not of nasal polyps in the middle meatus for differentiating chronic rhinosinusitis without polyps (CRS) from chronic rhinosinusitis with nasal polyps (CRSwNP).

\section{Clinical presentation, assessment and classifications}

A clinical diagnosis is based on history and evaluation with endoscopy and computerized tomographic scanning.

Patients with CRS and patients suffering from CRSwNP both complain of nasal obstruction, discharge, facial pressure or pain, and smell disorders. These symptoms are present for a period of more than 3 months. The nature, severity, or duration of clinical complaints does not allow the clinician to distinguish CRS from CRSwNP. Anterior rhinoscopy is the basic tool of the physical examination that relates to determining the existence of pathology in the sinonasal passages. However, examination of the nasal passages beyond the anterior portion can be limited. Presently, the current subjective diagnosis paradigm for chronic rhinosinusitis is most cost-effective but least accurate.

Endoscopy and/or CT screening were much better at appropriate diagnosis and targeted therapy but charges indicated a much higher cost (Stankiewitcz and Chow 2003). The nasal endoscopy, with use of a flexible fiberoptic endoscopes or rigid telescope, detects diseases missed on routine history or clinical examination and helps identify erythema, polyps or polypoid swelling, edema, crusting and mucopus. Finally, besides its essential function in preoperative evaluation, endoscopy could also have multiple uses in both the medical and surgical management of chronic rhinosinusitis: eg, in guiding microbiological sampling or biopsies (Kuhn 2004).

Although rhinosinusitis can be diagnosed in the majority of patients by using only the history and physical examination (including endoscopy), patients with persistent sinus disease, with recurrent or complicated sinus disease often require imaging studies. Several rhinosinusitis staging systems utilizing CT techniques are available (Zinreich 2004). Patients suffering from CRSwNP have higher CT scores at presentation and more severe symptoms (Deal and Kountakis 2004).

Based on these evidences, the experts of the American position paper agreed with a consensus classification of CRS for both clinical use and research purposes. CRS patients 


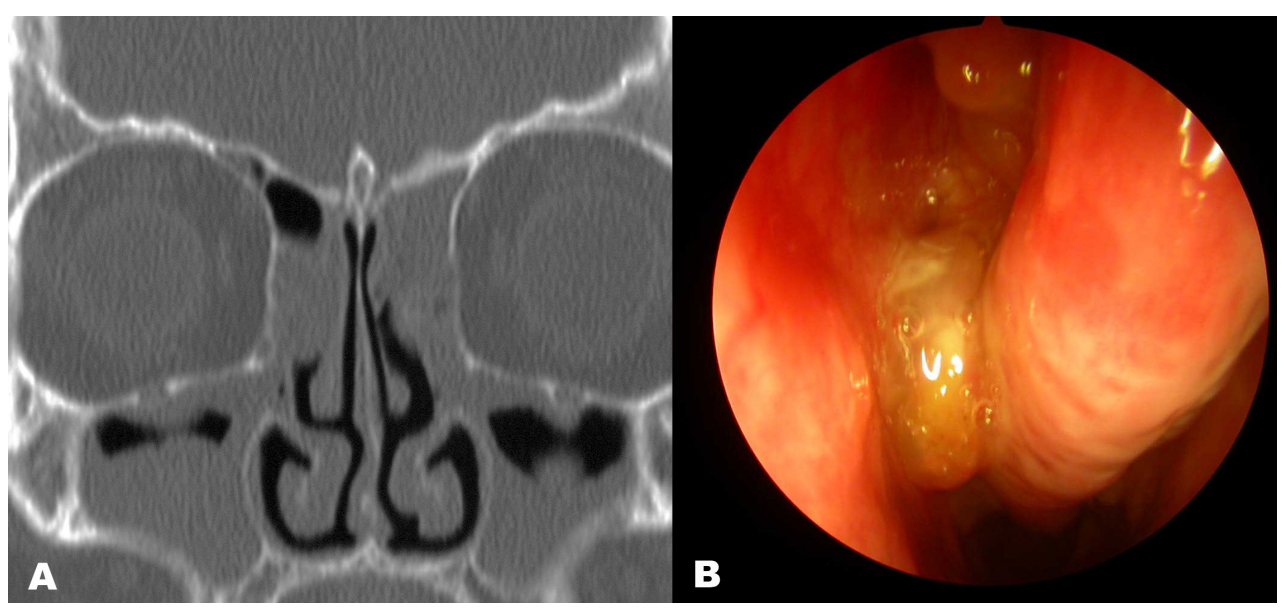

Figure I Clinical features: (A) CRS: CT scanner sinuses. Bilateral opacity of maxillary and ethmoid sinuses; (B) CRSwNP: endoscopic view ( $30^{\circ}$ Hopkins telescope, left nasal cavity). Nasal polyps in middle meatus.

should be categorized in function of the presence of endoscopically visible nasal polyps in middle meatus, of associated eosinophilic or other inflammatory features (Meltzer et al 2004a). Finally, the severity of symptoms is staged into mild, moderate, or severe in function of the trouble induced by CRS symptoms using a visual analogue scale or, when considering CRSwNP, in case of comorbidities (Fokkens et al 2005a).

\section{Pathogenesis}

The etiology of CRS and CRSwNP is multifactorial and comprises a vicious circle of pathophysiological, anatomical and constitutive factors. Various causative agents play a role in rhinosinusitis including microorganisms, allergic and non allergic immunologic inflammation and non infectious, non immunologic causes. The Table 2 summarizes the main factors considered as associated to or inducers of the CRS

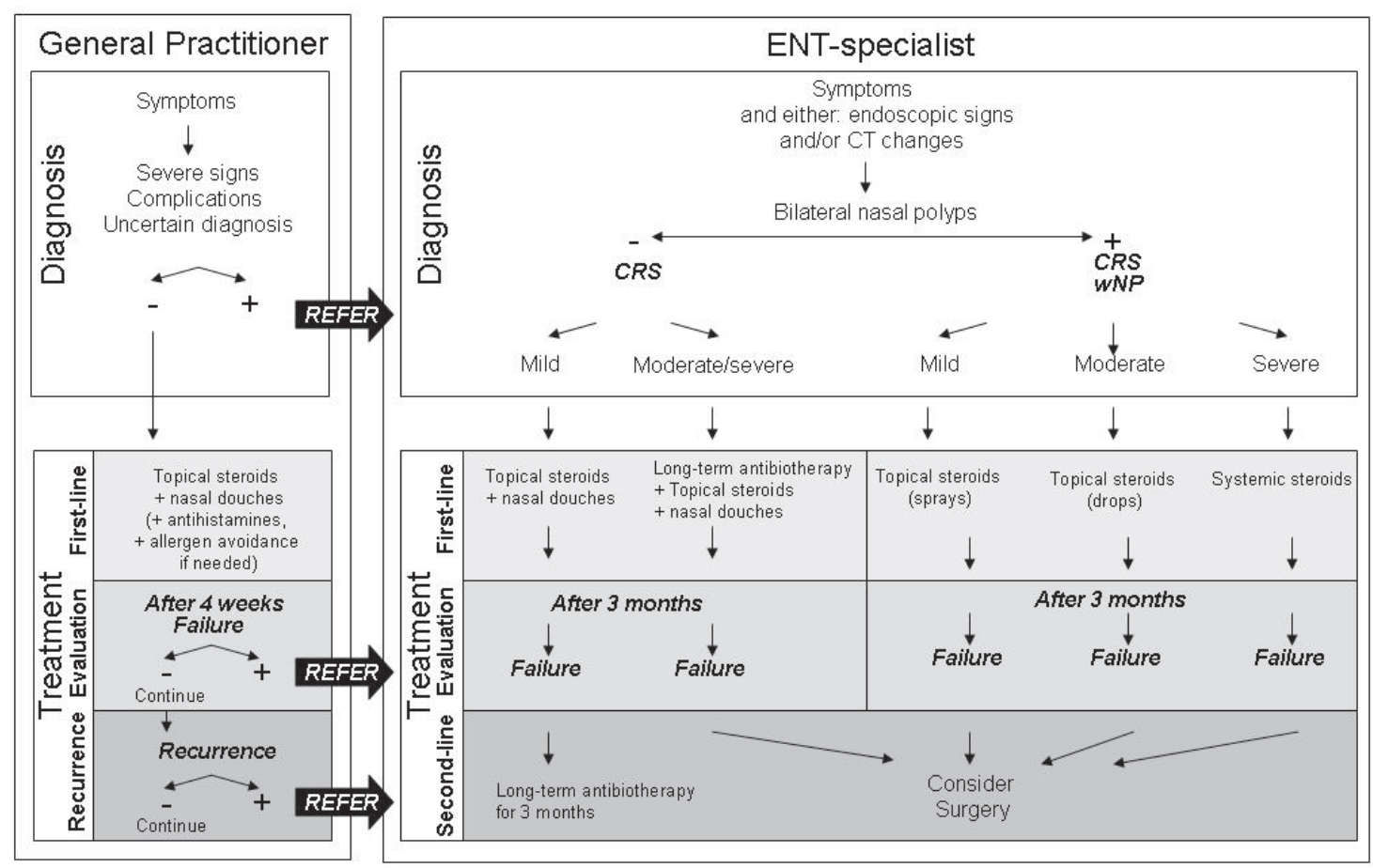

Figure 2 Flowchart for diagnosis and management of CRS and CRSwNP: view for General Practitioner and for Ear, Nose, and Throat specialist (Fokkens et al 2005a). 
Table I Clinical definition of rhinosinusitis/nasal polyps following the EP ${ }^{3}$ OS document (Fokkens et al 2005b)

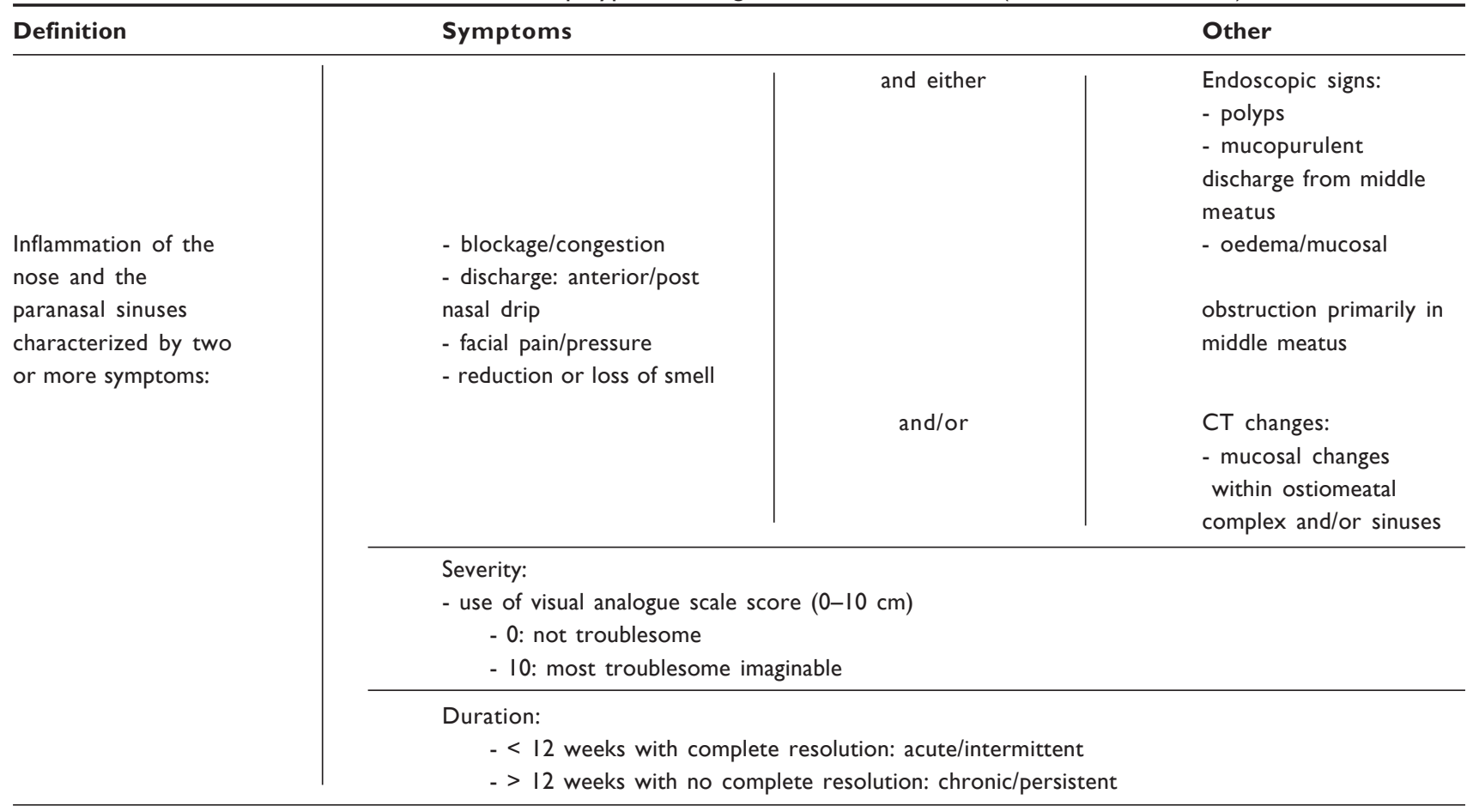

inflammatory reaction and identifies some potential targets for drug management.

The possible indirect contamination of sinus cavities during common cold has been evoked. During a common cold, nasal fluid containing viruses, bacteria and inflammatory mediators is blown into the sinuses where they produce mucosal edema, cellular infiltration, mucus thickening and infection (Puhakka et al 1998; Alho 2003, 2004).

There are more documented evidences about allergic and immunologic factors associated to the development of rhinosinusitis. Perennial allergic rhinitis has a statistically significant association with chronic and recurrent acute rhinosinusitis (Gutman et al 2004).

On a biological point of view, recent evidences suggest that, despite clinical similarities, CRS and CRSwNP are distinct entities with separate inflammatory pathways and cytokine profiles (Gillespie and Osguthorpe 2004). Examining the histology of middle turbinate tissues from patients with polypoid versus nonpolypoid disease might allow for distinction between these 2 entities. CRS is histopathologically characterized by a predominant neutrophilic inflammation with a lesser contribution of eosinophils. Furthermore, CRS is characterized by basement membrane thickening, goblet cell hyperplasia, and prominent subepithelial fibrosis. On the other hand, CRSwNP is characterized by eosinophilic inflammation. Besides an active eosinophilic recruitment and activation, histomorphologic characterization of CRSwNP also reveals frequent epithelial damage, variable stages of thickened basement membrane, and mostly edematous to sometimes fibrotic stromal tissue, with a reduced number of vessels and glands. The particular inflammatory reaction of CRSwNP could be partially explained by the following processes: latephase allergic inflammation in response to airborne allergens; dysregulation of sinus epithelium with overproduction of chemokines; T-cell activation in response to fungal antigens (hyphae); or in response to bacterial superantigens. It is clearly demonstrated that interleukin (IL)-5 and eotaxin could play a pivotal role in the latter process by recruiting and activating eosinophils. A discordance between systemic allergic phenotype and local inflammatory mechanisms leading to eosinophilic inflammation in nasal polyps was suggested because neither total immunoglobin $\mathrm{E}$ (IgE) concentrations nor eosinophilic cationic protein (ECP), IL-4, or IL-5 concentrations were found different in atopic versus nonatopic subjects. A role has been proposed for IgE specific for staphylococcal-derived superantigens in the pathogenesis of CRS associated with nasal polyps. Finally, different patterns in leukotriene production have been demonstrated in CRS with and without polyps (Perez-Novo et al 2005). 


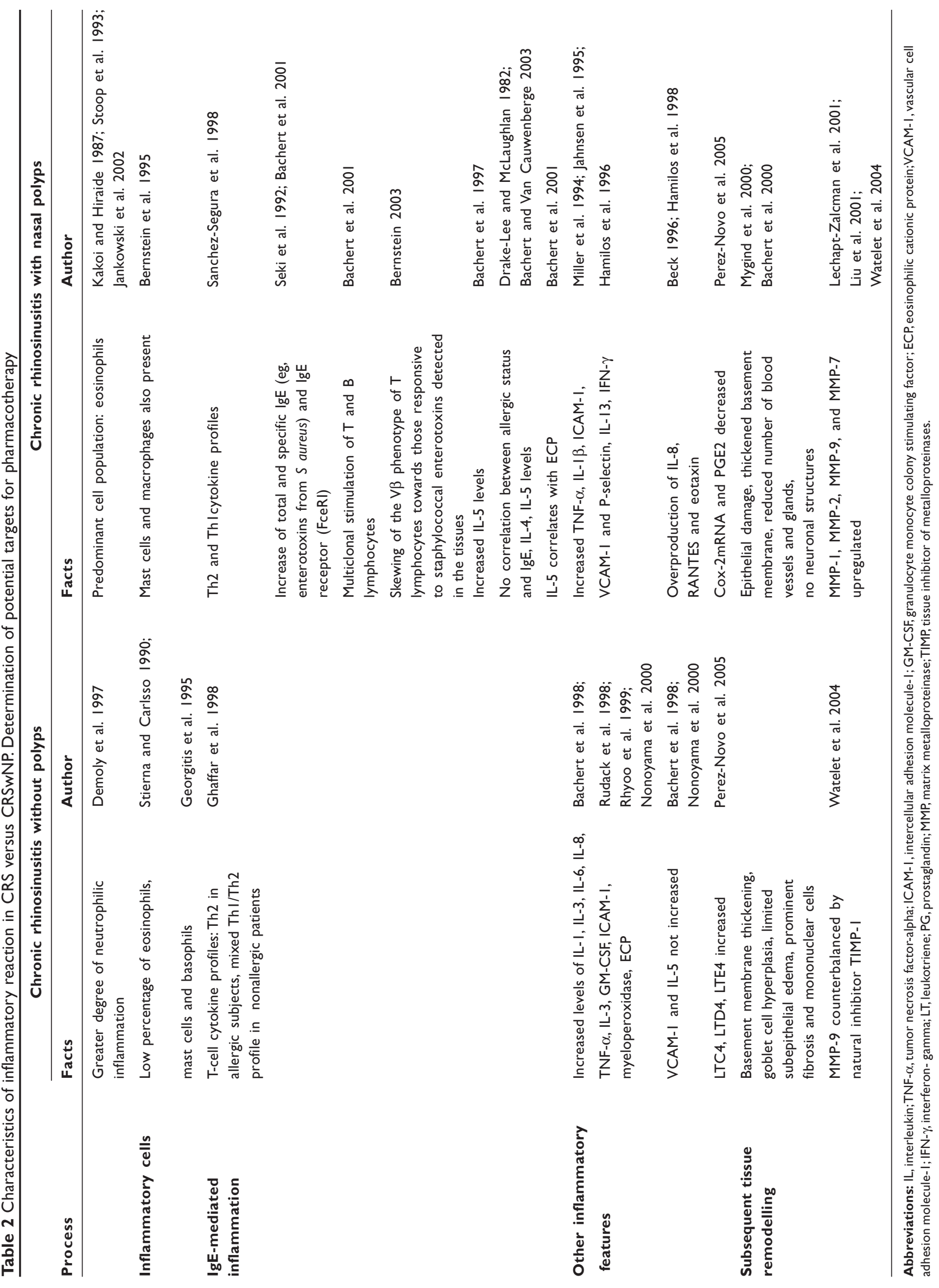


Other non inflammatory parameters have been suspected to induce or at least participate in the CRS evolution. Dysfunction of autonomic nerve pathways, other noninflammatory properties of leukotrienes, hyperresponsiveness or local irritation caused by gastroesophageal reflux were demonstrated in selected subsets of patients with rhinosinusitis and could participate in the pathogenesis of CRS. Defects in mucociliary clearance (eg, primary ciliary dyskinesia, cystic fibrosis, Young's syndrome, etc) and antibody deficiency syndromes predispose to rhinosinusitis like aspirin-associated respiratory diseases. Finally, as in the pathogenesis of allergy or asthma, the role of indoor or outdoor pollution and tobacco smoke has been suggested.

\section{Current treatments and guidelines}

Treatment aims to reduce the mucosal inflammation and swelling, to control infection, and restore aeration of the nasal and sinus mucosa.

A modern treatment of CRS should respect several principles.

First of all, it should consider the patient in totality: from etiology, when possible, till clinical features. When considering patients with CRS, comorbidities such as asthma must not be underestimated especially during the decision process for therapy.

A modern treatment for CRS should also reflect the new findings in pathogenesis. Even if the actual debate on initial causes or polyp formation is still active, the clinicians should try to categorize their patients in function of the presence or not of nasal polyps at the middle meatus. The clinical evolution seems to be significantly different between the groups. However, the nature and severity of inflammation or irreversible damages are usually difficult to be assessed in daily practice. At this regard, some clinical or biological criteria can be suggestive: eg, hypereosinophilic syndrome or hyper-IgE syndromes are regularly associated to CRSwNP.

A modern treatment of CRS should profit from the most recent pharmacological improvements. New classes of medications can be identified on the basis of pathogenesis knowledge. For example, the recent developments of specific drugs acting against cytokines or growth factors involved in the CRS course are illustrative of this evolution, like the inhibitors of the leukotriene cascade or immunomodulatory drugs. The different options for manipulating the T-cells responsible of the inflammatory reaction seem to be promising for patients suffering from allergies or asthma and probably will be applied soon in CRS treatments. Because of the multiplicity of interactions between targets, a subtle combination of molecules is probably needed and should increase the respective efficacy of the medical treatment of CRS. Finally, thanks to recent advances in pharmacokinetics, new ways of drug administration being developed.

A modern treatment of CRS should adapt its schemes to evidence-based medicine. Unfortunately, basic evidence on drug efficacy in CRS is still missing. As mentioned by the EP ${ }^{3}$ OS expert panel (Fokkens 2005), validated trials are lacking even for the most prescribed medications against CRS such as antibiotics.

Finally, as all treatment for chronic diseases, an adequate management of CRS should need a regular evaluation of efficacy and revision. A multidisciplinary approach and follow-up is mandatory as diseases such as cystic fibrosis can generate sinus diseases.

\section{Medical treatments}

Extensive reviews have been recently published on the medical management of chronic rhinosinusitis (Scadding 2004). Different classes of medications could be proposed to patients with CRS (Aukema and Fokkens 2004).

\section{Treatment of the causative agent}

When correctly identified and available, the first step of the treatment of CRS should be to manage the underlying cause. For example, oral antihistamines should be prescribed in patients with a proven allergy, but there is little evidence of their efficacy in CRS even with nasal polyps. Another example: proton pump inhibitors are the modality of choice for the treatment of gastroesophageal reflux associated with CRS, but the efficacy on sinus symptoms is limited (Ulualp, Toohill, et al 1999; DiBiaise et al 2002).

Considering infection as a causative factor for the development of CRS, systemic antibiotics are often administered to patients with chronic sinusitis and underlying bacterial infection. Oral broad spectrum antibiotics are indicated for the treatment of acute bacterial exacerbation of CRS. Amoxicillin and amoxicillin plus clavulanic acid remain the first choice (Dinis et al 2000; Passali et al 2001). Prolonged use of low-dose macrolides has been proposed (Suzuki and Ikeda 2002; Gillespie and Osguthorpe 2004; Siddiqui 2004; Wallwork and Coman 2004). The use of 
fluoroquinolones for upper respiratory tract infections has been evoked as acting against Gram-negative bacteria, Staphylococcus aureus, and Streptococcus pneumoniae. Reports exploring the efficacy of new generation of fluoroquinolone are available: levofloxacin (Hurst et al 2002; Gillespie and Osguthorpe 2004) and mostly moxifloxacin (Faich et al 2004). Finally, since Ponikau and colleagues (1999) suggested that chronic rhinosinusitis and nasal polyps have a fungal origin, there are now publications exploring the possible efficacy of nasal lavages with antimycotics in chronic rhinosinusitis (Ponikau et al 2002, 2005; Fergusson 2003).

Finally, environmental factors or allergic factors may predispose individuals to CRS. In these patients, the following preventive measures may be helpful: reduced exposure to pollution, cigarette smoke, dust, moulds, and other environmental chemical irritants.

\section{Treatment of sinus inflammation and subsequent damages}

It was suggested that antibiotics and nasal steroids are the basic treatment for CRS (Dolor et al 2001), whereas combination of systemic and local steroids are the foundation of CRSwNP (Gillespie and Osguthorpe 2004). Even if the relative importance of antibiotics is still actively debated in chronic mucopurulent rhinosinusitis (Sykes et al 1986), it is now well accepted that the background inflammatory reaction must be actively treated in CRS. Several studies about the topical glucocorticosteroids prescribed in CRS are available. They are considered as effective treatment in CRS with or without polyps as demonstrated by several randomized double-blind studies (Keith et al 2000; Parikh et al 2001; Giger et al 2003; Dijkstra et al 2004; Lund et al 2004; Patel et al 2004; Aukema et al 2005). However, these studies demonstrate only minor improvement in non-operated patients. This was partially explained by a lack of penetration into the sinuses by topically applied drugs. In CRS with eosinophilic inflammation, topical steroids are routinely prescribed for at least 3 to 6 months with few reports on systemic or local adverse events.

Other medical treatments have been discussed in the literature. The intranasal saline was shown to decrease nasal symptoms in chronic sinusitis (Taccariello et al 1999). It improves quality of life in patients with CRS and reduces the amount of secretions, postnasal drip, and the load of mediators in the secretions. Cromoglycate (Lomusol, Aventis Pharma, Paris, France) was not considered in the treatment of CRS.
Although there is little supporting evidence, nasal decongestants are commonly prescribed in patients suffering from CRS. A study using magnetic resonance imaging showed only a brief and transient decongestant effect on inferior and middle turbinates with no shrinking of maxillary and ethmoid linings after use of xylometazoline (Benammar-Englmaier et al 1990). Capsaicin and ipratropium bromide, indicated in different types of rhinitis, were never tried in clinical studies in patients with CRS.

Finally, there are only few data available on clinical trials with antileukotrienes in CRS (Ulualp, Sterman, et al 1999; Wilson et al 2001). No published clinical studies using anticytokines, anti-growth factors or anti-metalloproteinases agents have been reported for the treatment of CRS (Amrol and Murray 2005; Bachert et al 2005). Finally, there exists no report on immunomodulating agents in CRS.

\section{Surgical treatment}

Reviews on the surgical management of chronic rhinosinusitis have been recently published (Strong and Sender 2003; Witterick et al 2004).

Recent advances in endoscopic technology and a better understanding of the importance of the ostiomeatal complex in the pathophysiology of sinusitis have led to the development of functional endoscopic sinus surgery (FESS). FESS aims to remove pathologic mucosa inside the paranasal cavities of disease, to restore an adequate aeration and drainage of the sinuses. This surgical procedure is a common adjunct to medical therapy in the management of chronic rhinosinusitis and nasal polyposis. If symptoms persist after failure or partial or temporary relief after medical treatment, surgery should be proposed.

Postoperatively the majority of the patients experience significant reduction of headache, nasal obstruction, post nasal drip and are improved in Quality of Life scores (Damm et al 2002; Chiu et al 2004; Iro et al 2004). In patients with asthma, FESS improves peak expiratory flow and reduces the use of inhaled and systemic glucocorticosteroids (Dhong et al 2001; Palmer et al 2001; Dunlop et al 1999; Goldstein et al 1999; Ikeda et al 1999; Senior et al 1999). The importance of postoperative use of medications is still poorly demonstrated (Lavigne et al 2002).

\section{Identification of the needs}

From the EAACI position paper and state-of-the-art reports it appears that only a few studies have respected the highest standards for clinical trials and that, as a consequence, some 
essential information about the efficacy and safety of drug management in CRS are missing.

\section{Need of complementary data on CRS pathogenesis}

As suggested earlier in the Pathogenesis section, some fundamental debates are inducing doubts and misunderstandings in the clinician community. More evidence about the initialization and clinical course of CRS is clearly required. Models developed in fundamental research on microbiology and inflammation in CRS could find ways of combining the medications available and define new targets for therapy to prevent the development of sinus inflammatory disease and reduce the episodes of recurrences. Further research on clinical and biological categorization of patients could lead to new subclassifications and more adapted treatments for CRS patients.

\section{Need to address the patient in his/her totality}

Based on a better understanding of the basic physiopathology and a more systematic and complete description of clinical comorbidities, new concepts for preoperative evaluation and postoperative monitoring of CRS patients could be developed. For example, the assessment of comorbidities should merit evidence-based guidelines. Finally, the quality of life of CRS patients has only partially been explored (Smith 2004). Complementary data are needed and schemes for regular evaluation of quality of life or sleep disorders should be designed for CRS.

\section{Need of evidence in the currently- proposed medical treatment}

Using Shekelle's categories of evidence summarized in Table 3 (Shekelle et al 1999), only topical steroids and antimycotics were tested using double-blind placebo controlled studies or meta-analyses (Table 4). Antibiotics, local or topical for short- or long-term treatment, nasal douching, mucolytics, and proton pump inhibitors have a category III of evidence, based only on evidence from non-experimental descriptive studies. Data are not available for decongestants (oral, topical), oral antimycotics or antihistamines, immunotherapy and phytotherapy.

Randomized prospective long-term studies for efficacy of antibiotics (systemic or topical) are urgently needed in CRS. Because of its costs and potential risks of microbial resistance, the use of antibiotics must be evaluated using the best-designed protocols. Regarding decongestants, one of the most frequent drugs used in upper airway inflammation, their long-term positive or negative effects on the CRS course should merit more attention from researchers. Finally, the promising anti-inflammatory medications already used in several rhinitis trials, were never applied in CRS patients.

\section{Need of evidence in the current view of surgical treatment}

As with most surgical procedures, there is a paucity of randomized, controlled clinical trials examining the use of FESS in the management of CRS and CRSwNP (Chiu et al

Table 3 Sekelle's evidence scale. Reproduced with permission from Shekelle PG, Woolf SH, Eccles M, et al. 1999. Clinical guidelines: developing guidelines. BMJ, 318:593-6. Copyright (C) 1999. British Medical Journal.

\begin{tabular}{|c|c|c|}
\hline Category of evidence & Subcategory & Evidence obtained from: \\
\hline \multirow[t]{2}{*}{1} & a & Meta-analysis of randomized controlled trials \\
\hline & b & At least one randomized controlled trials \\
\hline \multirow[t]{2}{*}{ II } & a & At least one controlled study without randomization \\
\hline & $\mathrm{b}$ & At least one other type of quasi-experimental study \\
\hline \multirow[t]{4}{*}{ III } & & Nonexperimental descriptive studies: \\
\hline & & - or comparative studies \\
\hline & & - or correlation studies \\
\hline & & - or case-control studies \\
\hline \multirow[t]{4}{*}{ IV } & & - or expert committee reports \\
\hline & & - or opinions or clinical experience of \\
\hline & & respected authorities, \\
\hline & & - or both \\
\hline
\end{tabular}


Table 4 Current treatments for chronic rhinosinusitis and their respective category of evidence (Fokkens et al 2005a)

\begin{tabular}{l} 
Medications \\
\hline Antibiotics (topical, systemic) \\
Glucocorticosteroids (topical) \\
Glucocorticosteroids (systemic) \\
Antimycotics (local) \\
Antimycotics (oral) \\
Proton pump inhibitors \\
Bacterial lysates \\
Nasal douching \\
Mucolytics \\
Decongestants \\
Antihistamines \\
Immunotherapy \\
Phytotherapy
\end{tabular}

Category of evidence

III

Ib

IV

Ib

No data available III

IIb

III

III

No data available No data available No data available No data available

2004). There is also an urgent need to compare the functional effects of medical with surgical treatment of CRS and CRSwNP.

Although one recent report has been published about the integration of medical and surgical treatment (Ragab et al 2004), the way how to implement them in daily practice must be clarified. Step-wise approaches summarized in guidelines for general practitioners and ENT-specialists should be developed.

Furthermore, it is absolutely mandatory to design surveys to determine the precise nature, duration, and dosage of medication to be used before, during, and after the surgical procedure. Nowadays, the prescription of post-operative drugs remains purely arbitrary.

\section{Conclusions}

Because of its complex pathogenesis of CRS and the uncertainties regarding the precise role played by the involved processes, the current management of CRS remains empirical or based on expert opinions. Some requirements are clearly identified such as the need of complementary evidence on CRS pathogenesis, the need of addressing the patient in his totality, the need of evidence in the currently proposed medical treatment or in the current view of surgical management. The challenge of further research in this field will be to combine a complete fulfilling of the missing evidence and the active development of new therapeutic strategies.

\section{References}

Alho OP. 2004. Nasal airflow, mucociliary clearance, and sinus functioning during viral colds: effects of allergic rhinitis and susceptibility to recurrent sinusitis. Am J Rhinol, 18:349-55.
Alho OP. 2003. Paranasal bony structures and sinus functioning during viral colds in subjects with and without a history of recurrent sinusitis. Laryngoscope, 113:2163-8.

Amrol D, Murray JJ. 2005. Alternative medical treatment strategies for chronic hyperplastic eosinophilic sinusitis. Curr Opin Otolaryngol Head Neck Surg, 13:55-9.

Anand VK. 2004. Epidemiology and economic impact of rhinosinusitis. Ann Otol Rhinol Laryngol Suppl, 193:3-5.

Anon JB, Jacobs MR, Poole MD, et al. 2004. Antimicrobial treatment guidelines for acute bacterial rhinosinusitis. Otolaryngol Head Neck Surg, 130(1 suppl):1-45.

Aukema AA, Fokkens WJ. 2004. Chronic rhinosinusitis: management for optimal outcomes. Treat Respir Med, 3:97-105.

Aukema AA, Mulder PG, Fokkens WJ. 2005. Treatment of nasal polyposis and chronic rhinosinusitis with fluticasone proprionate nasal drops reduces need for sinus surgery. J Allergy Clin Immunol, 115:1017-23.

Bachert C, Wagemann M, Hauser U, et al. 1997. IL-5 synthesis is upregulated in human nasal polyp tissue. J Allergy Clin Immunol, 99:8337-42.

Bachert C, Wagemann M, Rudack C, et al. 1998. The role of cytokines in infectious sinusitis and nasal polyposis. Allergy, 53:2-13.

Bachert C, Gevaert P, Holtappels G, et al. 2000. Nasal polyposis: from cytokines to growth. Am J Rhinol, 14:279-90.

Bachert C, Gevaert P, Holtappels G, et al. 2001. Total and specific IgE in nasal polyps is related to local eosinophilic inflammation. $J$ Allergy Clin Immunol, 107:607-14.

Bachert C, Van Cauwenberge P. 2003. Nasal polyposis and sinusitis. In: Adkinson, Yunginger J, Busse W, et al (eds). Allergy: principles and practice $6^{\text {th }}$ ed. St Louis: Mosby, pp 1421-36.

Bachert C, Watelet JB, Gevaert P, et al. 2005. Pharmacological management of nasal polyposis. Drugs, 65:1537-52.

Beck LA, Stellato C, Beall LD, et al. 1996. Detection of the chemokine RANTES and endothelial adhesion molecules in nasal polyps. $J$ Allergy Clin Immunol, 98:766-80.

Benammar-Englmaier M, Hallermeier JK, Englmaier B. 1990. Alphamimetic effects on nasal mucosa in magnetic resonance tomography. Digitale Bilddiagn, 10:46-50.

Benninger MS, Ferguson BJ, Hadley JA, et al. 2003. Adult chronic rhinosinusitis: definitions, diagnosis, epidemiology and pathophysiology. Otolaryngol Head Neck, 129(suppl 1):S1-S32.

Bernstein JM, Gorfien J, Noble B. 1995. Role of allergy in nasal polyposis: a review. Otolaryngol Head Neck Surg, 113:724-32.

Bernstein JM, Ballow M, Schlievert PM, et al. 2003. A superantigen hypothesis for the pathogenesis of chronic hyperplastic sinusitis with massive nasal polyposis. Am J Rhinol, 17:321-6.

Blomgren K, Alho OP, Ertama L, et al. 2005. Acute sinusitis: Finnish clinical practice guidelines. Scand J Infect Dis, 37:245-50.

Brink AJ, Cotton MF, Feldman C, et al. 2004. Guidelines for the management of upper respiratory tract infections. S Afr Med J, 94(6 Pt 2):475-83.

Chiu AG, Kennedy DW. 2004. Surgical management of chronic rhinosinusitis and nasal polyposis: a review of evidence. Curr Allergy Asthma Rep, 4:486-9.

Damm M, Quante G, Jungehueslsing M, et al. 2002. Impact of functional endoscopic sinus surgery on symptoms and quality of life in chronic rhinosinusitis. Laryngoscope, 112:310-15.

Deal RT, Kountakis SE. 2004. Significance of nasal polyps in chronic rhinosinusitis: symptoms and surgical outcome. Laryngoscope, 114:1932-5

Demoly P, Crampette L, Mondain M, et al. 1997. Myeloperoxidase and interleukin-8 levels in chronic sinusitis. Clin. Exp Allergy, 27:672-5.

Dhong HJ, Jung YS, Chung SK, et al. 2001. Effect of endoscopic sinus surgery on asthmatic patients with chronic rhinosinusitis. Otolaryngol Head Neck Surg, 124:99-104. 
DiBaise JK, Olusola BF, Huerter JV, et al. 2002. Role of GERD in chronic resistant sinusitis: a prospective, open label, pilot trial. $\mathrm{Am}$ $J$ Gastroenterol, 97:843-50.

Dijkstra MD, Ebbens FA, Poublon RM, et al. 2004. Fluticasone proprionate aqueous nasal spray does not influence the recurrence rate of chronic rhinosinusitis and nasal polyps 1 year after functional endoscopic sinus surgery. Clin Exp Allergy, 34:1395-400.

Dinis PB, Monteiro MC, Martins ML, et al. 2000. Sinus tissue pharmacokinetics after oral administration of amocicillin/ clavulanic acid. Laryngoscope, 110:1050-5.

Dolor RJ, Witsell DL, Hellkamp AS, et al. 2001. Comparison of cefuroxime with or without intranasal fluticasone for the treatment of rhinosinusitis. The CAFFS trial: a randomized controlled trial. JAMA, 286:3097-105.

Drake-Lee AB, McLaughlan P. 1982. Clinical symptoms, free histamine and IgE in patients with nasal polyposis. Int Arch Allergy Appl Immunol, 69:268-71.

Dunlop G, Scadding GK, Lund VJ. 1999. The effect of endoscopic sinus surgery on asthma: management of patients with chronic rhinosinusitis, nasal polyposis and asthma. Am J Rhinol, 13:261-5.

Faich GA, Morganroth J, Whitehouse AB, et al. 2004. Clinical experience with moxifloxacin in patients with respiratory tract infections. Pharmacother, 38:749-54.

Ferguson BJ. 2003. Antifungal nasal washes for chronic rhinosinusitis: what's therapeutic-the wash or the antifungal? J Allergy Clin Immunol, 111(5):1137-8.

Fokkens W. 2005. Evidence-based diagnosis and treatment of rhinosinusitis and nasal polyps. Rhinology, 43:1.

Fokkens W, Lund V, Bachert C, et al. 2005a. EAACI Position Paper on Rhinosinusitis and Nasal Polyps: executive summary. Allergy, 60:583-601.

Fokkens W, Lund V, Bachert C, et al. 2005b. European Academy of Allergology and Clinical Immunology. European position paper on rhinosinusitis and nasal polyps. Rhinol Suppl, 18:1-87.

Georgitis JW, Matthews BL, Stone B. 1995. Chronic sinusitis: characterization of cellular influx and inflammatory mediators in sinus lavage fluid. Int Arch Allergy Immunol, 106:416-21.

Ghaffar O, Durham S, Al-Ghambi K, et a1. 1998. Expression of heavy chain transcripts in the sinus mucosa of atopic and nonatopic patients with chronic sinusitis. Am J Respir Cell Mol Biol, 18:706-11.

Giger R, Pasche P, Cheseaux C, et al. 2003. Comparison of onceversus twice-daily use of beclomethasone diproprionate aqueous nasal spray in the treatment of allergic and non-allergic chronic rhinosinusitis. Eur Arch Otorhinolaryngol, 260:135-40.

Gillespie MB, Osguthorpe JD. 2004. Pharmacologic management of chronic rhinosinusitis, alone and with nasal polyposis. Curr Allergy Asthma Rep, 4:478-85.

Goldstein MF, Grundfast SK, Dunsky EH, et al. 1999. Effect of functional endoscopic sinus surgery on bronchial asthma outcomes. Arch Otolaryngol Head Neck Surg, 125:314-19.

Grevers G, Klemens A. 2002. Rhinosinusitis. Current diagnostic and therapeutic aspects. MMW Fortschr Med, 127:31-5.

Gutman M, Torres A, Keen KJ, et al. 2004. Prevalence of allergy in patients with chronic rhinosinusitis. Otolaryngol Head Neck Surg, 130:545-52.

Hamilos DL, Leung DY, Wood R, et al. 1996. Eosinophil infiltration in nonallergic chronic hyperplastic sinusitis with nasal polyposis is associated with endothelial VCAM-1 upregulation and expression of TNF-alpha. Am J Respir Cell Mol Biol, 15:443-50.

Hamilos DL, Leung DY, Huston DP et al. 1998. GM-CSF, IL-5 and RANTES immunoreactivity and mRNA in chronic hyperplastic sinusitis with nasal polyposis. Clin Exp Allergy, 28:1145-52.

Hurst M, Lamb HM, Scoot LJ, et al. 2002. Levofloxacin: an updated review of its use in the treatment of bacterial infections. Drugs, 62:2127-67.
Ikeda K, Tanno N, Tamura G, et al. 1999. Endoscopic sinus surgery improves pulmonary function in patients with asthma associated with chronic sinusitis. Ann Otol Rhinol Laryngol, 108:355-9.

Iro H, Mayr S, Wallisch C, et al. 2004. Endoscopic sinus surgery: its subjective medium-term outcome in chronic rhinosinusitis. Rhinology, 42:200-6.

Jahnsen FL, Haraldsen G, Aanesen JP, et al. 1995. Eosinophil infiltration is related to increased expression of vascular cell adhesion molecule1 in nasal polyps. Am J Respir Cell Mol Biol, 12:624-32.

Jankowski R, Bouchoua F, Coffinet L, et al. 2002. Clinical factors influencing the eosinophil infiltration of nasal polyps. Rhinology, $40: 173-8$.

Kakoi H, Hiraide F. 1987. A histological study of formation and growth of nasal polyps. Acta Otolaryngol, 103:137-44.

Keith P, Nieminen J, Hollingworth K, et al. 2000. Efficacy and tolerability of fluticasone proprionate nasal drops 400 microgram once daily compared with placebo for the treatment of bilateral polyposis in adults. Clin Exp Allergy, 30:1460-8.

Klossek JM, Federspil P. 2005. Update on treatment guidelines for acute bacterial sinusitis. Int $J$ Clin Pract, 59:230-8.

Kuhn FA. 2004. Role of endoscopy in the management of chronic rhinosinusitis. Ann Otol Rhinol Laryngol, 193:15-8.

Lavigne F, Cameron L, Renzi PM, et al. 2002. Intrasinus administration of topical budesonide to allergic patients with chronic rhinosinusitis following surgery. Laryngoscope, 112:858-64.

Lechapt-Zalcman E, Coste A, d'Ortho MP, et al. 2001. Increased expression of matrix metalloproteinase-9 in nasal polyps. J. Pathol, 193:233-41.

Liu CM, Hong CY, Shun CT, et al. 2001. Matrix metalloproteinase-1 and tissue inhibitor of metalloproteinase- 1 gene expressions and their differential regulation by proinflammatory cytokines and prostaglandin in nasal polyp fibroblasts. Ann Otol Rhinol Laryngol, 110:1129-36.

Lund VJ, Black JH, Szabo LZ, et al. 2004. Efficacy and tolerability of budesonide aqueous nasal spray in chronic rhinosinusitis patients. Rhinology, 42:57-62.

Meltzer EO, Hamilos DL, Hadley JA, et al. 2004a. Rhinosinusitis: establishing definitions for clinical research and patient care. $J$ Allergy Clin Immunol, 114:S155-S212.

Meltzer EO, Hamilos DL, Hadley JA, et al. 2004b. Rhinosinusitis: establishing definitions for clinical research and patient care. Otolaryngol Head Neck Surg, 131(6 suppl):S1-62.

Miller CH, Pudiak DR, Hatem F, et al. 1994. Accumulation of interferon gamma-producing Th1 helper T cells in nasal polyps. Otolaryngol Head Neck Surg, 111:51-8.

Mygind N, Dahl R, Bachert C. 2000. Nasal polyposis, eosinophil dominated inflammation, and allergy. Thorax, 55(suppl 2):S79-83.

Nonoyama T, Harada T, Shinogi J, et al. 2000. Immunochemical localization of cytokines and cell adhesion molecules in maxillary sinus mucosa in chronic sinusitis. Auris Nasus Larynx, 27:51-8.

Palmer JN, Conley DB, Dong RG, et al. 2001. Efficacy of endoscopic sinus surgery in the management of patients with asthma and chronic sinusitis. Am J Rhinol, 15:49-53.

Parikh A, Scadding GK, Darby Y, et al. 2001. Topical corticosteroids in chronic rhinosinusitis: a randomized double-blind, placebocontrolled trial using fluticasone proprionate aqueous nasal spray. Rhinology, 39:75-9.

Passali D, Mazzei T, Novelli A, et al. 2001. Amoxicillin/clavulanate in chronic rhinosinusitis: tissue and serum distribution. Acta Otorhinolaryngol Belg, 55:259-64.

Patel RS, Shaw RS, Wallace AM, et al. 2004. Efficacy and systemic tolerability of mometasone furoate and betamethasone sodium phosphate. J Laryngol Otol, 118:866-71.

Perez-Novo CA, Watelet JB, Claeys C, et al. 2005. Prostaglandin, leukotriene, and lipoxin balance in chronic rhinosinusitis with and without nasal polyposis. J Allergy Clin Immunol, 115:1189-96. 
Ponikau JU, Sherris DA, Kern EB, et al. 1999. The diagnosis and incidence of allergic fungal sinusitis. Mayo Clin Proc, 74:877-84.

Ponikau JU, Sherris DA, Kita H, et al. 2002. Intranasal antifungal treatment in 51 patients with chronic rhinosinusitis. J Allergy Clin Immunol, 110:862-6.

Ponikau JU, Sherris DA, Weaver A, et al. 2005. Treatment of chronic rhinosinusitis with intranasal amphotericin B: a randomized, placebo-controlled, double-blind pilot trial. J Allergy Clin Immunol, 115:125-31.

Poole MD, Portugal LG. 2005. Treatment of rhinosinusitis in the outpatient setting. Am J Med, 118(suppl 7a):45S-50S.

Puhakka T, Makela MJ, Alanen A, et al. 1998. Sinusitis in common cold. J Allergy Clin Immunol, 102:403-8.

Ragab SM, Lund VJ, Scadding G. 2004. Evaluation of the medical and surgical treatment of chronic rhinosinusitis: a prospective, randomized, controlled trial. Laryngoscope, 114:923-30.

Ray NF, Baraniuk JN, Thamer M, et al. 1999. Healthcare expenditures for sinusitis in 1996: contributions of asthma, rhinitis, and other airway disorders. J Allergy Clin Immunol, 103:408-14.

Ressel G. 2004. Sinus and Allergy Health Partnership releases report on adult chronic rhinosinusitis. Am Fam Physician, 69:2248-9.

Rhyoo C, Sanders SP, Leopold DA, et al. 1999. Sinus mucosal IL-8 gene expression in chronic rhinosinusitis. J Allergy Clin Immunol,103:395-400.

Rudack C, Stoll W, Bachert C. 1998. Cytokines in nasal polyposis, acute and chronic sinusitis. Am J Rhinol, 12:383-8.

Sanchez-Segura A, Brieva JA, Rodriguez C. 1998. T lymphocytes that infiltrate nasal polyps have specialized phenotype and produce a mixed Th1/Th2 pattern of cytokines. J Allergy Clin Immunol, 102:953-60.

Scadding GK. 2004. Medical management of chronic rhinosinusitis. Immunol Allergy Clin North America, 24:103-18.

Shekelle PG, Woolf SH, Eccles M, et al. 1999. Clinical guidelines: developing guidelines. BMJ, 318:593-6.

Seki H, Otsuka H, Pawankar R. 1992. Studies on the function of mast cells infiltrating in nasal polyps. Nippon Jibjinkoka Gakkai Kaiho, 95:1012-21.

Senior BA, Kennedy DW, Tanabodee J, et al. 1999. Long-term impact of functional endoscopic sinus surgery on asthma. Otolaryngol Head Neck Surg, 121:66-8.

Siddiqui J. 2004. Immunomodulatory effects of macrolides: implications for practicing clinicians. Am J Med, 117(Suppl 9A):26S-29S.

Smith TL. 2004. Outcome research in rhinology: chronic rhinosinusitis. ORL J Otolaryngol Relat Spec, 66:202-6.

Stankiewicz JA, Chow JM. 2003. Cost analysis in the diagnosis of chronic rhinosinusitis. Am J Rhinol, 17:139-42.
Stierna P, Carlsso B. 1990. Histopathological observations in chronic maxillary sinusitis. Acta Otolaryngol, 110:450-8.

Stoop AE, van der Heijden HA, Biewenge J, et al. 1993. Eosinophils in nasal polyps and nasal mucosa: an immunohistochemical study. $J$ Allergy Clin Immunol, 91:616-22.

Strong EB, Sender EW. 2003. Surgery for severe rhinosinusitis. Clin Rev Allergy Immunol, 25:165-76.

Suzuki H, Ikeda K. 2002. Mode of action of long-term low-dose macrolide therapy for chronic sinusitis in the light of neutrophil recruitment. Curr Drug Targets Inflamm Allergy, 1:117-26.

Sykes DA, Wilson R, Chan KL, et al. 1986. Relative importance of antibiotic and improved clearance in topical treatment of chronic mucopurulent rhinosinusitis. A controlled study. Lancet, 2:359-60.

Taccariello M, Parikh P, Darby Y, et al. 1999. Nasal douching in chronic rhinosinusitis: a randomised, single-blind study comparing alkaline nasal douche and sterile sea water, Rhinology, 37:29-32.

Ulualp SO, Toohill RJ, Hoffmann R, et al. 1999. Possible relationship of gastroesophagopharyngeal acid reflux with pathogenesis of chronic sinusitis. Am J Rhinol, 13:197-202.

Ulualp SO, Sterman BM, Toohill RJ. 1999. Antileukotriene therapy for the relief of sinus symptoms in aspirin triad disease. Ear Nose Throat J, 78:604-6.

Van Cauwenberge P, Watelet JB. 2000. Epidemiology of chronic rhinosinusitis. Thorax, 55(suppl 2):S20-21.

Varonen H, Sainio S. 2004. Patients' and physicians' views on the management of acute maxillary sinusitis. Scand J Prim Health Care, 22:22-6.

Wallwork B, Coman W. 2004. Chronic rhinosinusitis and eosinophils: do macrolides have an effect? Curr Opin Otolaryngol Head Neck Surg, 12:14-7.

Watelet JB, Bachert C, Claeys C, et al. 2004. Matrix metalloproteinases MMP-7 and MMP-9 and their tissue inhibitor TIMP-1: expression in chronic sinusitis versus nasal polyposis. Allergy, 59:54-60.

Wilson AM, White PS, Gardiner Q, et al. 2001. Effects of leucotriene receptor antagonist therapy in patients with chronic rhinosinusitis in areal life rhinologic clinic setting. Rhinology, 39:142-6.

Winstead W. 2003. Rhinosinusitis. Prim Care, 30:137-54.

Witterick IJ, Kolenda J. 2004. Surgical management of chronic rhinosinusitis. Immunol Allergy Clin North America, 24:119-34.

Wright ED, Frenkiel S. 2005. Infectious adult rhinosinusitis: etiology, diagnosis and management principles. J Otolaryngol, 34(suppl 1):S7-13.

Zinreich SJ. 2004. Imaging for staging of rhinosinusitis. Ann Otol Rhinol Laryngol, 193:19-23. 
